\title{
High Grade Uterine and Rectal Prolapse
}

\author{
Călin Molnar', Octavian-Sabin Tătaru², Vlad-Olimpiu Butiurcă', Varlam-Claudiu Molnar³ \\ 1 Surgery Clinic No. I, County Emergency Clinical Hospital, University of Medicine and Pharmacy, Tîrgu Mureș, Romania \\ 2 Urology Clinic, County Emergency Clinical Hospital, University of Medicine and Pharmacy, Tîrgu Mureș, Romania \\ 3 Obstetrics and Gynecology Clinic No. 1, County Emergency Clinical Hospital, University of Medicine and Pharmacy, Tîrgu Mures, \\ Romania
}

\section{CORRESPONDENCE}

Octavian-Sabin Tătaru

Str. Gheorghe Marinescu nr. 1

540103 Tîrgu Mureș, Romania

Tel: +40 758919891

E-mail: sabin.tataru@gmail.com

\section{ARTICLE HISTORY}

Received: 5 July, 2016

Accepted: 20 July, 2016
Călin Molnar • Str. Gheorghe Marinescu nr. 38 , 540139 Tîrgu Mures, Romania, Tel: +40 265215551 Vlad-Olimpiu Butiurcă • Str. Gheorghe Marinescu nr. 38, 540139 Tîrgu Mureș, Romania, Tel: +40 265 215551

Varlam-Claudiu Molnar - Str. Gheorghe Marinescu nr. 38, 540139 Tîrgu Mureș, Romania, Tel: +40 265 215551

\begin{abstract}
Introduction: Pelvic floor hernias are encountered especially in elderly women. A combined genital, bladder, and rectal prolapse poses treatment challenges in aged women. Case presentation: We present the case of an 88 year-old patient, complaining of an intravaginal mass protruding for the last 3 months, rectal prolapse that occurred two weeks before admittance, accompanied by stress incontinence of urine and chronic constipation. Examination revealed a uterine prolapse with cystocele and a fourth grade rectal prolapse. We decided on a perianal and transvaginal approach, performing preliminary dilatation and curettage, cervix amputation, anterior colporrhaphy and colpoperineorrhaphy (Manchester procedure) with perineal rectosigmoidectomy using the LigaSure ${ }^{\mathrm{TM}}$ device, and coloanal manual anastomosis. Postoperatively the patient had no symptoms of stress urinary incontinence, bowel movement resumed in the fourth postoperative day, and the patient was discharged after seven days. One month after surgery the patient has both urinary and fecal continence, with no relapse in pelvic organ prolapse. Conclusions: Encountering genital, bladder, and rectal prolapse in the same patient is quite rare, and its treatment can be difficult in aged women. Therefore, a less invasive surgical procedure, using the transvaginal approach, and a genital sparing surgery could be the key in cases like this.
\end{abstract}

Keywords: anterior colporraphy, cystocele, rectal prolapse, transanal rectosigmoid resection

\section{INTRODUCTION}

The primary management strategy for severe uterine prolapse is surgical. There are abdominal/laparoscopic and vaginal approaches. The fixation of the sacrospinous ligament and the uterosacral ligament suspension are vaginal reconstructive interventions that have a low complication rate and an proficient costbenefit ratio. ${ }^{1}$ Uterosacral suspension is generally seen as more successful than sacrospinous uteropexy. ${ }^{2}$

There are 2 types of approaches in the surgical treatment of rectal prolapse: abdominal procedures and perineal procedures. For an elderly patient, with lots of comorbidities,we believe that choosing a surgical intervention with low morbidity and mortality rate with shorter recovery time is a goal in management of such patients. 


\section{CASE PRESENTATION}

We present the case of an 88 year-old patient from a rural background admitted to Surgery Clinic No. I of the County Emergency Clinical Hospital of Tîrgu Mureş with the following complaints: pelvic mass protruding for the last 3 months, followed by a rectal prolapse that occurred two weeks before admittance, accompanied by urine stress incontinence and chronic constipation. From the patient's history we found that she had two term pregnancies (natural delivery), and had no early terminated pregnancies. Clinical and ultrasound examination revealed a uterine prolapse with cystocele and a fourth grade rectal prolapse (Figure 1). Following a full clinical and biological investigation, we decided on a perianal and transvaginal approach, performing preliminary dilatation and curettage, cervix amputation with the help of the LigaSure ${ }^{\mathrm{TM}}$ device, anterior colporrhaphy and colpoperineorrhaphy (Manchester procedure) with perineal rectosigmoidectomy using the LigaSure ${ }^{\mathrm{TM}}$ device and coloanal manual anastomosis (Figure 2).

The urethral bladder catheter was removed after two days, with no symptoms of stress urinary incontinence, bowel movement resumed in the fourth postoperative day, and the patient was discharged after seven days. The histopathology report grossly describes a $30 \times 20 \times 20 \mathrm{~mm}$, slightly irregular uterine cervix, and a $95 \times 60 \mathrm{~mm}$ rectum with a mesorectum without pathological signs. Microscopically there is evidence of epithelium hyperkeratosis with chronic cervicitis, and signs of hyperplastic crypts, with smooth muscle fibers and chronic inflammatory signs. Three months postoperatively the patient has both urinary and fecal continence with no relapse in pelvic organ prolapse.

\section{DISCUSSION}

The patient's personal surgical history, her risk for intraoperative or postoperative complications, as well as the recurrence of uterus prolapse and clinical aspects affect the surgical therapeutical approach. Moreover, the reconstruction routes include laparoscopic and robotic methods. In the USA the majority of reconstructive operations for prolapse (80-90\%) are performed using the transvaginal approach. ${ }^{3}$

Maher et al. (2004) showed that there are significantly longer operating times, a higher rate of complications, bigger costs and longer hospital admission for the abdominal route compared to the transvaginal one. ${ }^{4}$

During the $18^{\text {th }}$ century, in England, Donald A. performed the first procedure in which the uterovaginal prolapse was surgically treated with an anterior and posterior

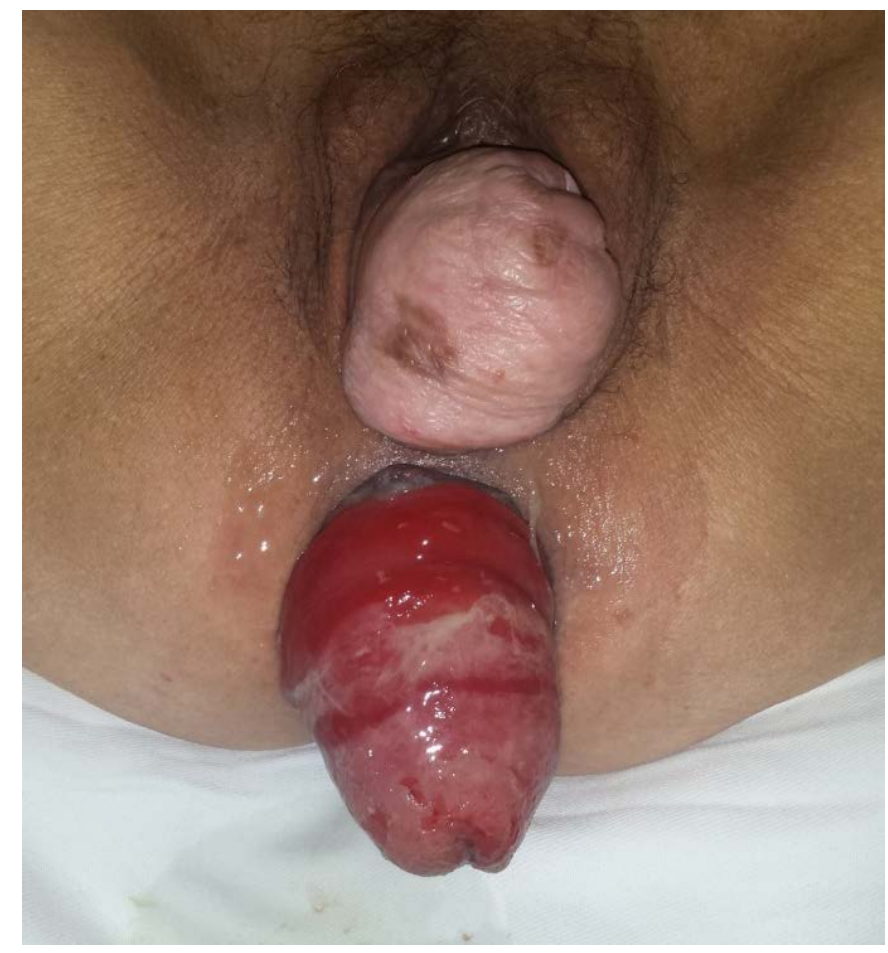

FIGURE 1. Preoperative aspect - Cystocele with fourth grade uterine prolapse and rectal prolapse.

colporraphy and amputation of the cervix. The technique was named the Manchester procedure. ${ }^{5}$

Sexual functioning or pregnancy was not taken into consideration because our patient was not sexually active, and because pregnancy was not possible due to her age.

The resection of the rectum and the sigmoid by a transperineal approach consists of the full removal of the rectum and the colon through the anal canal, completing the operation with a coloanal anastomosis. In general, patients who undergo a perineal rectosigmoidectomy are elder patients, with multiple associated pathologies and higher surgical risk. ${ }^{6}$

The mortality rate for the perineal resection of the rectosigmoid is $0-5 \%$, and the percent of reappearance ranges from $0 \%$ to $16 \%$. Older patiens with comorbidities, who have a higher operating risk or contraindication for the transabdominal approach, are the best candidates for the transperineal route. ${ }^{7}$ In comparative studies, the Manchester technique showed to have a lower mortality and morbidity rate in relation to the anatomical result, compared to the vaginal hysterectomy, in case of uterine prolapse. ${ }^{8}$

\section{CONCLUSIONS}

Encountering genital, bladder, and rectal prolapse in the same patient is quite rare, but it can be corrected in the 


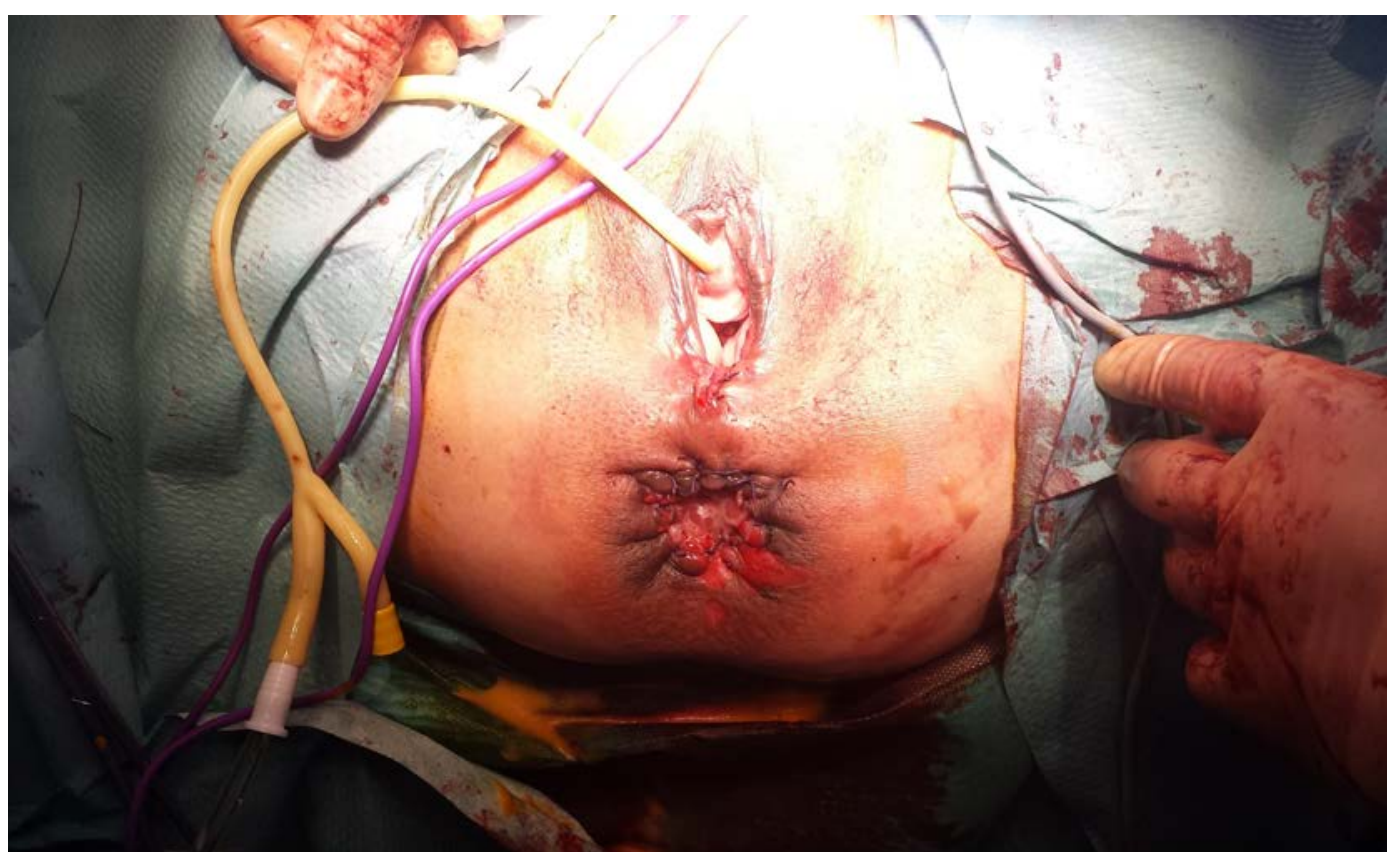

FIGURE 2. Postoperative clinical aspect - Manchester and perinealrectosigmoidectomy performed with vesico-urethral catheter in place.

same setting by surgical approach. Surgery can pose serious challenges and can be difficult in aged women. Therefore, a less invasive surgical procedure, using only the transvaginal approach, and a genital sparing surgery could be the key to success in cases like this.

\section{ACKNOWLEDGEMENTS}

Călin Molnar, Claudiu-Varlam Molnar and Vlad-Olimpiu Butiurcă were the pre-, intra- and postoperative treatment team. Călin Molnar was responsible for surgical management, design and interpretation of data, and critically revised the manuscript along with Claudiu-Varlam Molnar, Octavian Sabin Tătaru and Vlad-Olimpiu Butiurcă. All authors were involved in drafting the manuscript, selecting the references and critically revising the manuscript. All authors read and approved the final manuscript.

\section{COMPETING INTERESTS}

The authors declare that they have no conflict of interests, and that they have no financial interests related to the material in the manuscript.

\section{FUNDING}

We state that the authors did not receive any funding for this manuscript.

\section{CONSENT}

Written informed consent was obtained from the patient for the publication of this report and any accompanying images. A copy of the written consent is available for review by the Editor-in-chief of this Journal.

\section{REFERENCES}

1. Betschart C, Cervigni M, Contreras Ortiz O, et al. Management of apical compartment prolapse (uterine and vault prolapse): A FIGO Working Group report. Neurourol Urodyn. 2015 Oct 20. doi: 10.1002/nau.22916. [Epub ahead of print]

2. Dietz $\mathrm{V}$, Vaart $\mathrm{CH}$, Graaf $\mathrm{Y}$, et al. One-year follow-up after sacrospinous hysteropexy and vaginal hysterectomy for uterine descent: a randomized study. Int Urogynecol J. 2010;21(2):209-216.

3. Hamilton BS, Weber AM, Meyn L. Procedures for pelvic organ prolapse in the United States, 1979-1997. Am J Obstet Gynecol. 2003;188(1):108-115.

4. Maher CF, Qatawneh AM, Dwyer PL, Carey MP, Cornish A, Schluter PJ. Abdominal sacral colpopexy or vaginal sacrospinouscolpopexy for vaginal vault prolapse: a prospective randomized study. Am J Obstet Gynecol. 2004:190(1):20-26.

5. Donald A. A short history of the operation of colporrhaphy, with remarks on the technique. J Obstet Gynaecol Br Emp. 1921;28:256-259.

6. Varma M, Rafferty J, Buie WD. Standards Practice Task Force of American Society of Colon and Rectal Surgeons. Practice parameters for the management of rectal prolapse. Dis Colon Rectum. 2011;54(11):1339-1346.

7. Williams JG, Rothenberger DA, Madoff RD, Goldberg SM. Treatment of rectal prolapse in the elderly by perinealrectosigmoidectomy. Dis Colon Rectum. 1992;35(9):830-834.

8. Dietz V, Schraffordt Koops SE, van der Vaart $\mathrm{CH}$. Vaginal surgery for uterine descent; which options do we have? A review of the literature. Int Urogynecol J Pelvic Floor Dysfunct. 2009;20(3):349-356. 